\title{
NOSOLOGÍA, PROFILAXIS Y VALOR MÉDICO LEGAL DE LAS INFECCIONES DE TRANSMISIÓN SEXUAL EN LOS PROCESOS POR VIOLACIÓN EN CHILE (1890-1920)
}

\author{
Alejandra Palafox Menegazzi \\ Universidad Autónoma de Chile, Chile \\ Email: alejandra.palafox@uautonoma.cl \\ ORCID iD: https://orcid.org/0000-0003-1936-5432
}

Recibido: 6 noviembre 2019; Aceptado: 31 mayo 2020

Como citar este artículo/Citation: Palafox Menegazzi, Alejandra (2021) "Nosología, profilaxis y valor médico legal de las infecciones de transmisión sexual en los procesos por violación en Chile (1890-1920)", Asclepio, 73(1): p343. https://doi.org/10.3989/asclepio.2021.09

RESUMEN: Desde la segunda mitad del siglo XIX, el creciente desarrollo del movimiento médico-higienista y su indisoluble combinación con el movimiento eugenésico, promovieron en Chile la paulatina implantación institucional de medidas dirigidas al conocimiento, tratamiento y erradicación de la blenorragia, la sífilis y el chancro blando, variantes de las llamadas enfermedades vergonzosas, concebidas como enfermedades de trascendencia social desde la década de 1920. En este artículo buscamos conocer la valoración médico-legal de la trasmisión de estas afecciones, durante la comprobación de agresiones sexuales tipificadas como violación, en Santiago y Valparaíso -principales ciudades del país- entre los años 1890 y 1920. Tras considerar los conocimientos médicos y las perspectivas morales desde las que se analizaban los contagios y los delitos sexuales tratados, así como su valoración forense, se analiza la implementación práctica de estas disposiciones en los procesos judiciales.

PALABRAS CLAVE: Medicina Legal; Delito de Violación; Enfermedades Venéreas; Chile; 1890-1920.

\section{NOSOLOGY, PROPHYLAXIS AND LEGAL MEDICAL VALUE OF SEXUALLY TRANSMITTED INFECTIONS IN RAPE PROCESSES IN CHILE (1890-1920)}

\begin{abstract}
Since the second half of the 19th century, the growing development of the medical-hygienist movement and its indissoluble combination with the eugenics movement, promoted in Chile the gradual institutional implementation of measures aimed at knowledge, treatment and eradication of gonorrhoea, syphilis and sort chancre, variants of the so-called shameful diseases, conceived as diseases of social importance since the 1920s. In this article we seek to know the medical-legal assessment of the transmission of these conditions, during the verification of sexual aggressions typified as rape, in Santiago and Valparaíso - main cities of the country - between 1890 and 1920. After considering the medical knowledge and moral perspectives from which the contagions and the sexual crimes treated, as well as their forensic assessment, the practical implementation of these provisions in judicial proceedings is analyzed.
\end{abstract}

KEY WORDS: Legal Medicine; Crime of Rape; Venereal Diseases; Chile; 1890-1920. 


\section{INTRODUCCIÓN}

Desde la segunda mitad del siglo XIX, el creciente desarrollo del movimiento médico-higienista y su indisoluble combinación con el movimiento eugenésico promovieron en Chile la paulatina implantación institucional de medidas dirigidas al conocimiento, tratamiento y erradicación de las llamadas "enfermedades venéreas" ${ }^{\prime \prime}$ "vergonzosas", concebidas como enfermedades de trascendencia social desde la década de 1920 (Labarca, 2008, p. 89 y Vetö, 2014). Fue a finales de esa centuria, por otro lado, cuando el proceso de institucionalización de la Medicina Legal, iniciado en 1833 con el establecimiento de la cátedra homónima en la Escuela de Medicina, vivió un proceso de consolidación, materializado -entre otros hitos- en la fundación de la Morgue de Santiago en 1879, la primera sistematización nacional de sus conocimientos en 1900 (Puga, 1900), o el establecimiento de la materia como ramo obligatorio, en la Facultad de Medicina en 1901 (Fabregat, 2019) y en 1902 en la de Leyes y Ciencias Políticas de la Universidad de Chile (Muñoz, 1911, pp. 250-251).

Durante estas décadas, algunos médicos de ciudad pasaron a figurar como médicos legistas, al recibir el encargo de asistir con sus conocimientos a los tribunales. En relación con la justicia criminal, estos facultativos debían determinar la responsabilidad penal de un procesado mediante el examen de sus capacidades mentales, así como coadyuvar a comprobar empíricamente la comisión delictiva, estableciendo la edad, el sexo, la profesión y la identidad de un individuo, identificando lesiones en su cuerpo o averiguando la causa de su muerte (Puga, 1900, p. 5).

El crimen de violación -tipificado en el artículo 361 del Código Penal de 1874 como el acto de yacer con una mujer bajo tres circunstancias específicas: haciendo uso de fuerza o intimidación; cuando la mujer se hallase privada de sentido o razón o cuando ésta fuese menor de doce años cumplidos ${ }^{2}$ - podía dejar, según los principales representantes de la Medicina Legal en Chile, signos visibles en el cuerpo de víctimas y agresores, tales como marcas de lucha o resistencia de la víctima, lesiones genitales o el contagio de infecciones (Muñoz, 1911, pp. 201-202 y Puga, 1900, pp. 71-79).

En este artículo buscamos conocer la valoración médico-legal de la trasmisión de las llamadas enfermedades venéreas, durante la comprobación de agresiones sexuales tipificadas como violación en Santiago y Valparaíso - principales centros del país- entre los años 1890 y $1920^{3}$. Iniciamos nuestro estudio en unos años en los que la unión entre medicina y justicia recién, en
1887, se había materializado en la obligatoriedad de los facultativos de asistir a los tribunales en los asuntos forenses en los que fueran requeridos (Zañartu, 1894, 658). Una década en la que, tras la epidemia de cólera que asoló el país, se institucionalizó un discurso higienista de prevención y profilaxis de las enfermedades contagiosas -consideradas efectos de las condiciones socio-ambientales de los procesos de industrialización- a través de la creación del Consejo Superior de Higiene Pública en 1892 (Vetö, 2014) y en la que el laboratorio logró implantarse, a nivel teórico, como principal método de diagnóstico ante posibles contagios sexuales (Ríos, 1894, p. 97). Cerramos el periodo en 1920, antecediendo el desarrollo de las sólidas campañas estatales de educación sexual que tuvieron lugar en los años siguientes como método profiláctico ante las temidas "enfermedades venéreas" (Labarca, 2008 y Vetö, 2014), y moviéndonos en un marco temporal en el que los discursos acerca de su nosología, tratamiento y prevención quedaron reducidos a una literatura restringida y dirigida a un público especializado.

Tras considerar los conocimientos médicos y las perspectivas morales desde las que se analizaban los contagios y los delitos sexuales tratados, así como las carencias científicas del conjunto de procedimientos periciales aplicados, nuestra hipótesis es que la valoración de estas afecciones como método probatorio criminal obstaculizó en mayor medida la demostración de un delito de violación.

Para su comprobación, con objeto de conocer las principales aproximaciones higienistas nacionales sobre las infecciones de transmisión sexual, su interacción dinámica con la comunidad científica internacional, así como su relación con las condiciones materiales de los dos centros urbanos señalados, hemos revisado detenidamente la colección Revista Médica de Chile (RMC), primer órgano de difusión de esta rama del conocimiento, que, pese a editarse en Santiago, daba cobertura a noticias y publicaciones extranjeras, así como a trabajos provenientes de distintas partes del país.

Así mismo, hemos analizado el tratamiento forense de estas afecciones durante la comprobación del delito de violación, revisando las obras de quienes fueron profesores titulares de la cátedra de Medicina Legal de la Universidad de Chile, el médico Federico Puga Borne y el jurista Tomás Ramírez Frías, autores de las primeras obras didácticas en esta materia ${ }^{4}$. Pese a estar orientados a públicos diversos y publicarse en momentos diferentes, cabe advertir que las obras de ambos autores confluyeron en sus valoraciones y que no 
encontramos contradicciones entre ambas, siendo las apreciaciones de Puga Borne más específicas desde el punto de vista médico-científico, como cabría esperar.

Por último, hemos revisado cien expedientes judiciales, incoados por este delito en las ciudades de Santiago y Valparaíso, atendiendo -cuantitativa y cualitativamente- al desarrollo de los informes periciales realizados sobre supuestos agresores y víctimas del delito, los métodos de detección de infecciones sexuales y sus consecuencias en la resolución de los procesos, con el propósito de analizar la implementación práctica de las disposiciones recogidas en las obras anteriormente señaladas.

Adoptamos en nuestro análisis una perspectiva cultural, con enfoques de la criminología crítica, partiendo de la premisa de que la enfermedad, como el delito, son construcciones históricamente determinadas, que no existen, como tales, al margen de las sociedades que los norman y significan (Baratta, 2004, pp. 85, 88 y 109). A partir de aquí, buscamos ahondar en las interacciones simbólicas que permitieron la significación de las "enfermedades venéreas" y de la categoría delictiva "violación", a través del estudio de parte de la regulación e implementación de su comprobación forense.

Concebimos los tratados, artículos e informes periciales analizados como discursos científicos, aceptando su entidad textual e interpretándolos como elementos centrales en la construcción de la ciencia (Locke, 1997). Desde esta perspectiva, consideramos que los documentos analizados coadyuvaron a la construcción de una determinada realidad social, creando, reproduciendo y consolidando, material e ideológicamente, entre otras desigualdades, asimetrías en las relaciones de género imperantes (Scott, 1990, pp. 23-58 y West, 2000, p. 181). Con objeto de deconstruir estas desigualdades, partimos de la premisa de que estos relatos, producidos con valor de "verdad", estuvieron atravesados y, a su vez, promovieron determinados modelos normativos sobre los ámbitos adecuados de la experiencia femenina y masculina (Rudolph, 2008: 928), re-significando valores relativos al cuerpo, la pureza y la honorabilidad de las mujeres, presentes desde época colonial (Araya, 2004, p. 81), dentro de nuevos parámetros cientificistas.

Recuperamos en nuestra perspectiva algunos aspectos de la heterogénea y controvertida Historia Global, a través de la obra de Joseph Conrad, al centrarnos en las intersecciones entre los procesos globales y las manifestaciones locales, considerados como elementos interrelacionados, no opuestos, en un periodo an- terior al proceso histórico de la Globalización (Conrad, 2016, p. 11-12). Con ello, pretendemos contribuir al estudio de la formación de la sexualidad como dispositivo discursivo de control, valorando de qué forma ésta contribuyó a la re-significación y el reforzamiento de la desigualdad entre hombres y mujeres, desde un enfoque "glocal", que permita insertar estas dinámicas en el marco de las relaciones transfronterizas que lo posibilitaron. Recuperamos, al respecto, la idea de que lo global tiene propiedades sistémicas, más allá de las unidades que lo integran, que "la existencia de estas unidades locales son en buena medida resultado de procesos y resultados extra-locales" (Robertson, 2003, p. 21) y que el sentido de los fenómenos globales es siempre adaptado, moldeado y redefinido por las culturas locales, en funcion de sus necesidades, creencias y costumbres particulares (Robertson, 2006, p. 10).

A partir de estas consideraciones, abordamos nuestro objeto de estudio, recuperando el concepto de glocalismo para referirnos a una diversidad local inserta en modelos culturales compartidos. Es dentro de esta lógica que nos acercamos a la historia de la ciencia, concibiendo las fuentes teóricas (artículos de revista y obras didácticas) como un medio de "circulación de saberes" (Sanhueza, 2018, p. 18). Sobre los expedientes judiciales, incoados en Santiago y Valparaíso, su análisis nos permite observar cómo contextos locales distintos y específicos se movían dentro una globalidad compuesta por esquemas y modelos compartidos (en este caso referentes a la conceptualización médica y al tratamiento forense de las infecciones de transmisión sexual, concebidas como "enfermedades venéreas" por la comunidad científica internacional), conocimientos que fueron aplicados, apropiados y reconfigurados de manera distinta en cada contexto (Sanhueza, 2018, p. 15), de acuerdo con su particular idiosincrasia. Tratamos de observar, por tanto, la interacción de la teoría global (compuesta por un corpus teórico que partía de una autoridad académica internacional) con la cultura local, mediante el estudio de discursos y prácticas médico-forenses, insertos en un particular sistema de justicia.

\section{CRITERIO MÉDICO, HIGIENISMO Y EUGENESIA}

Desde finales del siglo XIX, tras la aparente tranquilidad de la República Parlamentaria, se fraguó en Chile una crisis social, moral y política, desencadenada en la época del Centenario (Ledezma, 2006), y que tuvo en su base, entre otros factores, un intenso pero desigual crecimiento económico, ligado principalmente a la exportación de salitre, que fomentó fuertes movimientos migratorios del campo a la ciudad, protagoni- 
zados principalmente por mujeres, lo que incrementó la población de la capital chilena y de su principal puerto, segmentando, de forma dramática, su distribución socioeconómica (Hutchison, 2006, p. 35-39; Urbina, 2001, p. 62-73).

La centralidad de ambos espacios urbanos dentro del proceso sanitario de mejora material impulsado desde el Estado (Cruz Coke, 1995, p. 431), contrastó, así, con una mayoritaria sociedad popular, que vivía en precarias condiciones de higiene, hacinada en reducidos ranchos y conventillos (Brito, 2005, pp. 30-37 y Urbina, 2001, p. 59). Ante esta situación, dentro de la llamada "cuestión social" (Grez, 1995, pp. 10-49), desde los sectores médico-higienistas -organizados desde 1869 en la Sociedad Médica de Santiago y, desde 1913, en la de Valparaíso- se abogó por contener y mejorar las condiciones sanitarias de los sectores populares, con el fin de erradicar las frecuentes y graves epidemias de cólera, viruela, fiebre tifoidea y tuberculosis, así como el contagio de afecciones de transmisión sexual, impulsando la asunción de la salubridad como asunto de estado (Cruz-Coke, 1995, pp. 389, 412-414, 475-478 y 543 y Cabrera, 2014, p. 74).

En este contexto, desde inicios del siglo XX, en el ámbito educativo, sanitario y criminológico se desarrolló un proceso de apropiación y reinterpretación de diversos principios eugénicos (Sánchez, 2015, pp. 53-57). Originada en las teorías de Francis Galton, la eugenesia (etimológicamente "ciencia del buen engendrar") constituía una propuesta médico social (Sánchez, 2014, p. 60), defensora de la intervención humana como medio para el control y la mejora de la población en términos evolutivos y hereditarios (Vetö, 2014), y concebida a principios del siglo XX como una solución frente a la supuesta degeneración biológica y moral que amenazaba a la raza humana, y que en Chile se relacionó, principalmente, con la pobreza (Sánchez, 2015, p. 103), aunque también con otros factores como la inmigración, el alcoholismo y las enfermedades venéreas.

Estos principios estuvieron muy presentes en la Liga Chilena de Higiene Social (LCHS), cuya fundación, en 1917, marcó el inicio de los programas de intervención eugenésica en Chile (Sánchez, 2015, p. 114) y cuyas aspiraciones, que incluían el control de la sexualidad -combatiendo determinados comportamientos aludidos como "vicio solitario, perversiones e inversiones" - tuvieron un marcado carácter moral y nacional, al estar orientadas al "supremo interés de la patria" (Liga Chilena de Higiene Social, 1921, p. 242). Entre sus objetivos principales figuró la erradicación de la sífilis, afección que, junto con la tuberculosis y el alcoholismo, formó parte de los llamados "venenos raciales", concebidos como causantes de la degeneración moral y racial de la nación (Sánchez, 2015, p. 111).

Dentro de este proceso de construcción higiénico y eugenésico de la sexualidad en el país, en relación con las "enfermedades venéreas", varios artículos incluidos dentro de la RMC dieron fe del creciente interés y preocupación científica hacia estas extendidas afecciones, así como de una evolución en su conceptualización, el conocimiento de su naturaleza y su valoración moral. Al respecto, el seguimiento y participación chilena en los estudios y debates que se dieron en el movimiento sanitario internacional, coordinado principalmente desde París y Bruselas (Barona, 2016, p. 5), en torno a estas infecciones quedó plasmado mediante el desarrollo de estadías formativo-científicas de algunos médicos en centros europeos, así como en la citación y transcripción de varios de los artículos de las principales publicaciones científicas del viejo continente (Boza, 1898, pp. 36-38). De esta manera, la revista se hizo eco de discursos en los que la nosología científica y la profilaxis terapéutica se entremezclaban indistintamente con valoraciones de índole higiénico y moral, defensoras de la castidad como mejor método preventivo.

De acuerdo con la extendida preocupación internacional frente al incremento del contagio entre la población en edad fértil, cuyo avance lastraba la valorada como fuerza de trabajo obrera y militar varonil, así como la considerada fuerza reproductora femenina, dentro del sistema de género imperante, la RMC dio cobertura a diversos discursos eugenésicos de corte nacionalista. Como se reproducía en 1915 , dentro del marco de la "Campaña Internacional contra las enfermedades venéreas", había que unir esfuerzos para sacar de "la conspiración del secreto" y combatir abiertamente un mal que atacaba al pueblo chileno -descrito como "varonil, esforzado y homogéneo hasta constituir el orgullo de nuestra raza" (Editorial, 1915, p. 329)-, al tiempo que debilitaba las consideradas "fuerzas vivas de la nación", atacando al ejército y a la marina, causando incalculables desgracias y sufrimientos y apagando "la vida de muchísimos seres que deberían constituir los mejores elementos con que mantener el standard de la raza humana" (Editorial, 1915, p. 327).

El mayor peligro asociado a este contagio, además de su incidencia en las causas de mortalidad, por tanto, fue su trascendencia sobre las "funciones y el producto de la generación", así como sobre la "decadencia" (Middleton, 1884, p. 429), la "degeneración" y la "esterilización" de la raza (Sociedad Médica de Valparaíso, 
1917, p. 365). El factor racial, de hecho, incrementó progresivamente su presencia en la valorización del origen, gravedad y consecuencias de la enfermedad a lo largo del periodo estudiado. Dentro de una heterogénea apropiación de las teorías de la degeneración y del darwinismo social europeo en el país (Durán, 2017 y Sánchez, 2014a) diversas voces se alzaron en defensa de la "raza chilena", concepto que abarcó desde aspectos biológicos hasta psicológicos, sociales y culturales y que estuvo ligado a un nacionalismo patriarcal, defensor de lo viril como valor superior -asociado a la fuerza y el orden, en contraposición con una feminidad asociada a lo inferior y lo débil (Araya, 2004)- y de la unidad sobre la base de una supuesta integración racial, como quedó reflejado en la obra del médico $\mathrm{Ni}$ colás Palacios, primer tratadista del concepto (Subercaseaux, 2007, pp. 54, 79-88).

De acuerdo con estos principios, en 1912, el doctor Eduardo Moore afirmaba que en "países muy cerrados a la inmigración" el contagio era relativamente "benigno", en comparación con la sífilis que "un nacional" contraía "de una extranjera", considerada "mucho más grave". La gravedad, en atención al artículo, aumentaba en función a la "distancia racial" existente, siendo "la sífilis de la Manchuria tomada por chileno (...) más grave que la tomada en Bolivia o Argentina, pero estas más graves que la chilena" (Moore, 1912, p. 90). En un contexto de creciente exaltación de los valores militares y patrióticos, ligado a acontecimientos como la Guerra del Pacífico, los conflictos fronterizos con Argentina (Durán, 2017, p. 48) o la llegada de inmigración europea (Subercaseaux, 2007, pp. 79 y 85), boliviana y asiática (Fernández, 2015 y Morimoto, 2004, pp. 46 y 198), es posible suponer que las referencias a extranjeros de Moore no fueron casuales.

Pese a la inserción de estas disertaciones en una lógica nacional-eugenésica, debemos considerar que en el país austral no se implementaron medidas de prevención desarrolladas en otras latitudes, tales como la obligatoriedad de presentar un certificado médico que acreditara la inexistencia de afecciones de transmisión sexual para poder acceder al matrimonio o la tipificación del delito de contagio, a pesar de su amplia demanda desde el ámbito médico y jurídico (Coutts, 1929; Elguero, 1857; Núñez, 1927; Sociedad Médica de Valparaíso, 1917 y Vidal, 1930).

\subsection{ESTEREOTIPOS Y CONTAGIO}

A pesar del carácter androcéntrico de la mayor parte de los escritos analizados, desarrollados en torno al varón como sujeto neutral y universal, y de la centralidad de la raza, comprendida como un concepto varo- nil, la revista reconoció que las investigaciones sobre infecciones de origen sexual habían sido mucho más profundas en los hombres que en las mujeres (Swisser, 1899, p. 455), aun siendo éstas las más perjudicadas por los contagios, ya que la manifestación interna de los síntomas en los cuerpos femeninos incrementaba las posibilidades de ignorar las enfermedades, lo que evitaba un tratamiento a tiempo y complicaba o imposibilitaba la reproducción de las afectadas (Ríos, 1894, p. 97).

La RMC abordó el contagio femenino mediante la adopción y el desarrollo de preceptos de género anclados en el ideal deontológico de madre-esposa (Brito, 2005), en un contexto general de tensión de la moral sexual imperante, ligado al incremento de la presencia femenina que se estaba produciendo en el espacio público (Gálvez, 2017 y Hutchison, 2006). Se reprodujo, de esta manera, una clasificación que dividía a las mujeres en dos grupos en función de su actividad sexual, desarrollando, por un lado, un discurso sobre las mujeres "honradas", cuya sexualidad estaba limitada al -legítimo pero no exento de riesgos- espacio del matrimonio (Fournier, 1906, p. 341), y otro sobre mujeres consideradas no honradas o dedicadas a la prostitución, actividad que estuvo tolerada y, desde finales de la década de 1890, reglamentada en varias ciudades del país hasta la promulgación del código Sanitario de $1925^{5}$, y que, durante nuestro periodo de estudio, siguió siendo considerada "la gran causa de la difusión" de estas afecciones (Lea-Plaza, 1913, p. 101), algo acorde con la tendencia internacional, como quedó puesto de manifiesto en el XVII Congreso Internacional de Medicina celebrado en Londres en agosto de 1913 y cuyos resultados fueron recogidos por la RMC (Sierra, 1914, pp. 20-26). Si bien, a partir de 1915, en el marco de la "Campaña Internacional contra las enfermedades venéreas", se reconoció respecto al contagio una responsabilidad compartida entre hombres y "prostitutas o meretrices privadas", la revista se mostró oficialmente partidaria de la reglamentación de esta actividad como medida profiláctica, junto con la promoción de campañas educativas de higiene sexual (Editorial, 1915, p. 325).

Dentro del ámbito médico, sin embargo, las demandas sobre el establecimiento de campañas institucionales contrarias a la prostitución fueron crecientes, materializándose a finales del periodo en la solicitud de parte de la Sociedad Médica de Valparaíso del desarrollo de "ligas contra las enfermedades venéreas", capaces de llevar a cabo una "campaña de moral y de cultura", que demostrara que "psicológicamente" la prostitución no era necesaria, sino contraria a 
la propagación de la especie, y que sociológicamente podía evitarse con poder de voluntad (Sociedad Médica de Valparaíso, 1917, p. 366), perspectiva acorde a los principios de la recién fundada LCHS, que buscaba promover una ética sexual basada en el "dominio de las pasiones", oponiéndosea a la llamada "teoría de la necesidad", como quedó recogido en sus estatutos de 1920 (Liga Chilena de Higiene Social, 1921, p. 239).

Junto con el género, la clase fue otra de las variables consideradas a la hora de valorar la incidencia y las características de las infecciones de transmisión sexual. La relación de los contagios con las categorizadas como "clases bajas", por su supuesta falta de higiene, conllevó el desarrollo y la consolidación de un conjunto de estereotipos, dentro de los cuales las "clases superiores" aparecían casi exentas de poder sufrir estos males (Vega, 1880, p. 247; Moore, 1912, p. 87 y Lea-Plaza, 1913, p. 100). Estas extendidas impresiones fueron cuestionadas en la RMC sólo por la recién creada Sociedad Médica de Valparaíso, quien en 1917 advirtió el carácter interclasista de los contagios sexuales, siendo estos frecuentes entre "todas las clases sociales” (Sociedad Médica de Valparaíso, 1917, p. 365).

\section{EL TRATAMIENTO MÉDICO LEGAL}

Como señalamos, la violación era un delito tipificado en 1874 como el acto de yacer con una mujer, haciendo uso de la fuerza o la intimidación, cuando la víctima fuese menor de doce años o cuando se hallase privada de sentido o razón. En atención a lo recogido en los principales manuales de Medicina Legal de la época, la comprobación material de este delito debía realizarse, entre otros aspectos, mediante la observación corporal de las supuestas víctimas y agresores.

Al respecto, para Puga Borne, quien desarrolló su disertación apoyándose principalmente en la obra del médico francés Ambroise Tardieu, la violación era un delito que ofendía tanto el cuerpo como el alma, dejando señales morales y físicas sobre las víctimas, que variaban en función de la edad, la condición y la frecuencia de las agresiones, siendo siempre más visibles y de mayor gravedad en mujeres pre-púberes y vírgenes (Puga, 1900, p. 71).

Los daños morales apreciables podían oscilar entre una palidez plomiza, reflejo de un cansancio y debilidad generalizados, síncopes, delirios, convulsiones, fiebres, sensaciones de intensa fatiga o palpitaciones, llegando, en los casos más graves, a significar el origen de una epilepsia o el motivo de un suicidio (Puga, 1900, pp. 79-80). De la observación de la conducta demos- trada por una víctima después del delito sufrido, por tanto, según este profesor de Medicinal Legal podían extraerse aspectos indicativos de la comisión delictiva.

En relación con los daños físicos, como también recogía Ramírez Frías, la comprobación médico-legal del delito de violación cometido en "doncellas", debía desarrollarse mediante la observación de su membrana himen, y, en mujeres no vírgenes, mediante la identificación de lesiones reconocibles en sus órganos sexuales y otras partes del cuerpo, lo que ofrecía mayores dificultades materiales, según los autores (Puga, 1900, p. 79 y Muñoz, 1911, p. 201).

El reconocimiento de la comunicación de alguna "afección violenta" (Muñoz, 1911, p. 202) o "enfermedad venérea" (Puga, 1900, p. 80) era otro de los procedimientos médico-legales posibles y, a diferencia de los anteriores, su comprobación requería el examen corporal no sólo de la víctima sino también del agresor. Frente a las fases que caracterizaban estas enfermedades, asociadas cada una de ellas a síntomas distintos y no siempre identificables a simple vista, Puga Borne indicaba las dificultades clínicas a la hora de establecer un diagnóstico fiable, pues, si bien su existencia no ofrecía dudas ante la presencia de úlceras o chancros, la aparición de flujo mucoso o blenorragia podía tener un carácter multicausal.

Como quedó recogido en la RMC, la blenorragia "simple", a diferencia de la "gonorreica", asociada a la presencia del gonococus de Neisser, se consideraba ligada a microbios que vivían en los genitales de las mujeres y que causaban infección por prácticas concretas tales como "el coito durante las reglas, la masturbación, el cateterismo mal ejecutado con sondas no limpias, los excesos de bebida y principalmente de cerveza, la acción del frío o los traumatismos" (Sociedad Médica de Chile, 1889, pp. 121-124). Ante esta situación, para certificar si una inflamación genital era debida a un contagio sexual, durante el reconocimiento forense, el médico, en un primer momento, tenía que comprobar si existía proceso supurativo en la uretra de la víctima, comprimiendo la misma con el dedo introducido en la vagina, para desarrollar después un análisis microscópico, con la ayuda de un "observador experto y con un objetivo poderoso de excelente definición" (Puga, 1900, p. 80-82).

Al respecto, debemos considerar que si bien la identificación en 1879 de la bacteria causante de la gonorrea por Albert Neisser y el posterior desarrollo del método de coloración de Hans Christian Gram habían consolidado, teóricamente, las técnicas de laboratorio en el diagnóstico de las infecciones sexuales en 
Occidente, frente a esta supuesta "revolución bacteriológica", el laboratorio tardó décadas aun en ser el principal método de diagnóstico y estudio de estas infecciones, gracias a la permanencia de procedimientos más tradicionales como las historias clínicas (Bowen, 2013: 67). En el panorama chileno, si bien, de acuerdo con los consensos internacionales, la metodología de laboratorio introducida en la medicina a mediados del siglo XIX (Cruz-Coke, 1995, p. 365) apareció desde 1894 como la única válida para establecer un diagnóstico realmente fiable de la presencia de enfermedades transmitidas sexualmente (Ríos, 1894, p. 97), durante nuestro periodo de estudio apenas llegó a implantarse (Editorial, 1915, p. 331 y Cano, 1921, p. 654), lo que tuvo, como veremos, importantes consecuencias en la práctica forense.

\section{PRAXIS JUDICIAL Y ARBITRIO}

Ante la ausencia de una especialización formativa, los médicos encargados de asistir a la justicia desde la segunda mitad del siglo XIX fueron los llamados "médicos de ciudad", formados en materia legal durante la carrera sólo con un ramo, obligatorio a partir de 1901 (Fabregat, 2019, p. 3). La experiencia laboral de algunos de ellos en la Morgue de Santiago, o en el ámbito forense de distintas ciudades, fue lo que les dotó del estatus necesario para autodenominarse como "médico-legistas". Ningún conocimiento formal, por tanto, los diferenciaba del resto de facultativos titulados.

De esta manera, junto con reconocidos médicos que trabajaban cotidianamente al interior de la Morgue de Santiago, como Eduardo Donoso Grille, Eduardo Lira Erráruriz, Sabino Muñoz Labbé o Luis Quinteros Encina, para el caso capitalino, auxiliaron a los tribunales también expertos en salud infantil, como el doctor Ricardo Peralta, médico del Hospital de niños Roberto del Río. Para el caso de Valparaíso, la composición de los médicos forenses también fue heterogénea. Así, junto con Daniel Carvallo, Secretario del Consejo Departamental de Higiene, y Enrique Deformes Villegas, médico interno del Hospital San Juan de Dios y docente en la Escuela Naval-facultativos encargados de más de la mitad de los informes consultados-, intervinieron también expertos en salud mental, como el doctor Manuel Segundo Beca, trabajador de la Casa de Orates y del Hospital de San Borja, y profesionales que firmaban y se presentaban ya como "médico legistas", tales como J. C. Zillemelo, Víctor Grossi, C. E. Durán u Oscar Marín. Pese a que,como quedó recogido en el artículo 242 del Código de Procedimiento Penal de 1906, la ley recomendaba que en delitos como la violación fueran nombradas como peritos personas "del mismo sexo" que la persona reconocida, en ambas ciudades, todos los expertos consultados entre 1890 y 1920 fueron hombres.

Su relación más o menos cercana a la labor forense, así como su grado de experiencia al respecto, no fueron, sin embargo, elementos directamente proporcionales a la calidad y la adecuación de los informes que presentaron. La ausencia de un protocolo legal que regulara la forma en la que debían realizarse los exámenes conllevó el desarrollo de certificados sujetos al arbitrio de los jueces -que eran quienes determinaba sus objetivos- y al de los propios facultativos, quienes decidían de qué manera efectuar el reconocimiento corporal de víctimas y victimarios y cómo interpretar sus observaciones empíricas.

\subsection{UNA DUDOSA METODOLOGÍA}

La redacción de los informes periciales, estuvo sujeta a una determinada retórica (Locke, 1997) -desarrollada a través de normas visibles en su extensión y estructura- $y$, en estos, las evidencias materiales fueron interpretadas por los peritos, a través de un conjunto de categorías cognitivas que estuvieron atravesadas por criterios y valores morales de diversa índole, y que constituyeron elementos activos en la creación de significados (Cabrera, 2003). Al respecto, encontramos informes escuetos, de uno o dos párrafos de longitud, en su mayoría, escritos en primera persona y compuestos por tres partes diferenciables: presentación, descripción e interpretación. La ausencia de detalles y referencias específicas sobre la manera en la que se desarrollaron las observaciones clínicas estuvo ligada a la autoridad que ejercían los médicos en la comprobación pericial encargada. El centro de los exámenes y su legitimidad recayeron, por tanto, en su autoría.

Las escasas referencias sobre la metodología empleada por los peritos para comprobar lesiones y el estado del himen de las víctimas indicaron siempre la introducción de los dedos en los cuerpos examinados. Siguiendo las indicaciones de Puga Borne, tras una observación general de posibles indicios de violencia en la vecindad de los genitales, el perito debía comprobar el estado del himen, mediante la introducción de estiletes o sondas (Puga, 1900, p. 85), resortes materiales que, sin embargo, no constaron en ninguno de los ochenta y ocho informes médicos revisados.

De esta manera, encontramos relatos de médicos de Santiago y Valparaíso, como Eduardo Donoso, quien certificó en 1894 que la joven revisada presentaba "huellas de haber sido desflorada recientemente", encontrándose la membrana del himen "completamente 
desgarrada", lo que posibilitaba la introducción "en la vagina del dedo medio"; el doctor Eduardo Lira, quien aseguró en un examen presentado en 1896 que la víctima examinada tenía una vagina "muy húmeda" que permitía "fácilmente la intromisión de los dedos" o el médico Manuel Segundo Beca, quien en 1900 comprobó la desfloración de una mujer mediante la inspección ocular y el tacto ${ }^{6}$.

Con excepción de los casos en los que las víctimas se encontraban hospitalizadas por la gravedad de sus lesiones, todos los reconocimientos analizados se realizaron en sus domicilios. Dentro de una desconfianza institucional ante las denuncias femeninas generalizada en el contexto occidental (Quinlan, 2007, p. 16 y Vigarello, 1999, p. 225) y que fue evidente en el marco chileno desde época colonial (Araya, 2015, p. 12; Araya, 1995, p. 78), en atención a lo recogido por Puga Borne, el perito debía acudir a los domicilios de las víctimas sorpresivamente, para impedir "cualquier preparativo capaz de inducirlo en error" (Puga, 1900, p. 85).

Si bien los informes tenían como objetivo servir de documentos probatorios en la determinación del delito durante el proceso, las observaciones de los médicos sobrepasaron esta esfera. Su experticia, además de la comprobación del acto criminal, les permitía desarrollar, desde la autoridad que la ciencia les confería, relatos dirigidos a valorar la honorabilidad no ya de las personas formalmente procesadas, sino de las víctimas, imbricando evidencias empíricas y juicios de valor relativos a sus actitudes, como consta en el informe de 1900 firmado por el doctor Carvallo de Valparaíso, quien constató que "a pesar" de que la víctima revisada no era virgen, había mostrado una extraordinaria resistencia para someterse al examen, "debida al pudor y manifestada con inocencia y candor", algo nunca visto en sus años de experiencia ${ }^{7}$. Los peritos fungían, así, como testigos expertos (Quinlan, 2007, p. 12), dentro de una dinámica fuertemente arraigada en el sistema judicial y basada en valorar la credibilidad de los implicados en función de comportamientos y actitudes situados al margen del hecho formalmente juzgado (Brangier y Barriera, 2015).

La mirada se fijaba, de esta manera, en la condición de las supuestas víctimas, con base, principalmente, en su conducta sexual, y no sólo en la constatación material del acto en sí, como lo demuestra el hecho de que, en la práctica totalidad de los informes analizados $^{8}$, los peritos examinaran el estado de su himen, con objeto de comprobar si estas habían sido desfloradas antes de la comisión delictiva. Si bien, esta variable no debía considerarse formalmente en la investigación de un delito de violación, según su definición penal, en la práctica, acorde con lo recogido en los manuales consultados, supuso un elemento valorado en la comprobación criminal, más allá de su relación con la identificación de posibles lesiones genitales recientes, al considerarse prueba de la honorabilidad femenina, en el caso de mujeres solteras, como quedó constatado en varios relatos judiciales, tanto de Santiago como de Valparaíso.

Durante la comprobación de este aspecto, por otro lado, en dos de los informes analizados de Valparaíso, los médicos Juan Johansen y Daniel Carvallo incluyeron referencias al color de los pechos de las víctimas, como signo probatorio de su actividad sexual previa al delito juzgado. Así, mientras que para Johansen una aureola oscurecida que "había perdido por completo el tinte sonrosado de la virginidad" era un indicador de que la víctima había sido "desflorada" antes de la agresión juzgada, para Carvallo que la aureola de los pechos de una víctima examinada conservara un "color rosado" era signo de que ésta no había "cohabitado" antes del delito ${ }^{9}$.

La evidente ausencia de un protocolo a la hora de llevar a cabo estas revisiones médicas y el desarrollo de exámenes arbitrarios, junto con la desigualdad socioeconómica entre víctimas y agresores, incrementó las posibilidades de determinar una resolución de los conflictos favorable estos últimos. Al respecto, debemos considerar que las víctimas, en su mayoría ${ }^{10}$, fueron niñas o mujeres jóvenes, de escasos recursos materiales y formativos. Los acusados, por el contrario, pese a pertenecer también en su mayoría a los sectores populares, presentaron una composición más heterogénea, figurando como tales desde jornaleros hasta socios de empresas textiles, presbíteros y cirujanos de marina, con una fuerte presencia de comerciantes y artesanos de clase media. Su posición, con respecto a la de las víctimas, fue siempre igual o superior.

Así lo evidencia el proceso contra Eduardo López, joven de familia acomodada, preso en Santiago en 1915 por la denuncia interpuesta por la familia de una joven de estracto popular y por las declaraciones autoinculpatorias de su supuesto cómplice, Tránsito Allende, quien habría desnudado, sujetado y tapado la boca con un pañuelo a la víctima para que López pudiera ejecutar con ella "el acto carnal"11.

La acusación se basó en la declaración de Allende y en el informe del médico Luis Quinteros Encina. En este último, se recogía: "la niña presenta en sus órganos genitales, en la horquilla de la vulva un pequeño desgarro, el cual ha sangrado fácilmente al introducir 
el dedo por la abertura del himen. La producción fácil de esta pequeña hemorragia en este punto, prueba que ha habido violación muy reciente"12.

Frente a esta situación, la posición socioeconómica del reo le permitió tener acceso a un valioso conocimiento, mediante el que elaboró una exitosa estrategia de defensa, deslegitimando dicho informe por su falta de profesionalidad y apoyándose en la reciente entrevista del por entonces Ministro de Justicia, el también médico Gregorio Amunátegui, publicada en el periódico Las Últimas Noticias. En ésta, Amunátegui abogaba por una reorganización de los servicios médico-legales, refiriéndose a las carencias materiales que adolecía la enseñanza de la materia en Chile, basada en estudios "exclusivamente teóricos". Estas declaraciones fueron interpretadas por el reo como prueba de una carencia formativa, unida a una extendida despreocupación profesional entre los peritos, quienes elaborarían sus informes arbitrariamente, perjudicando, según este testimonio, a los acusados.

Figura 1. "Servicios Médico-Legales. El proyecto de ley del ejecutivo", en Las Últimas Noticias, 18 de diciembre de 1915, recogido en ANHCh, Santiago, Criminal, 1914, caja 1295, exp. 7, f. 108

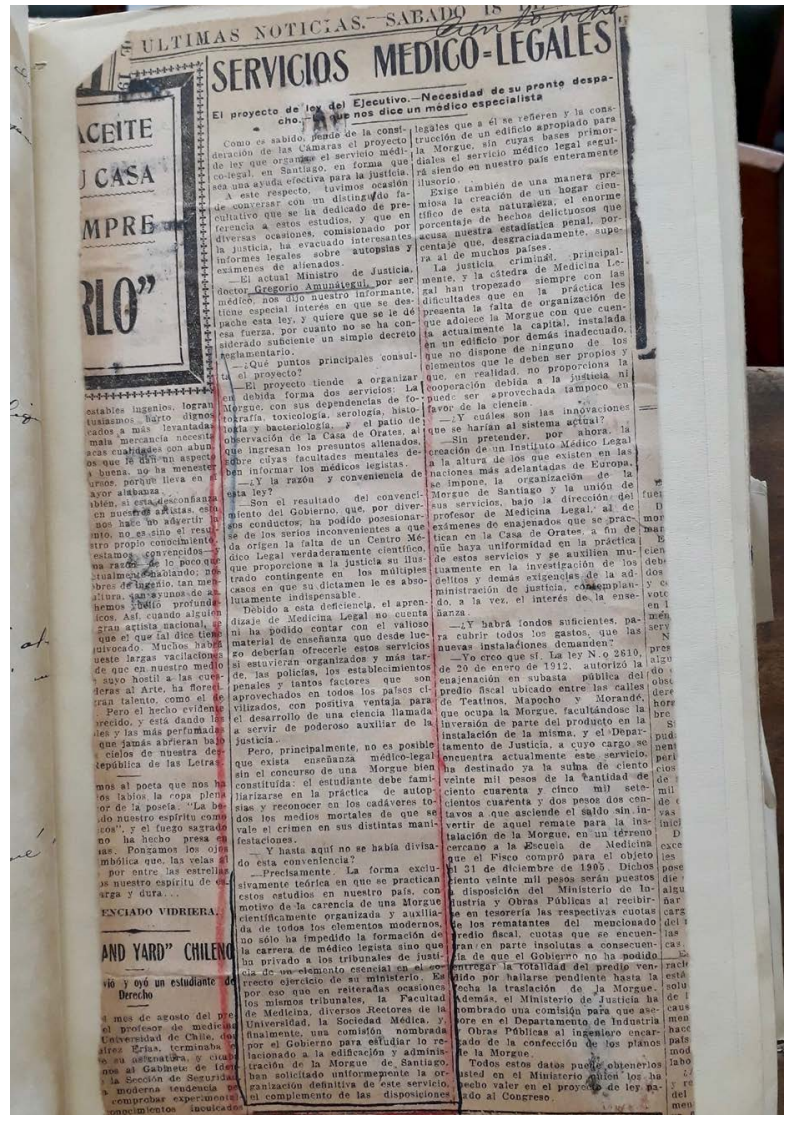

Mediante este alegato, junto con numerosas referencias a expertos en la materia, el reo logró cuestionar la autoridad del informe, criticando, entre otros aspectos, el empleo de los dedos en vez de estiletes y logrando que el juez ordenara su revisión por otro especialista. El elegido para la ocasión fue el médico legista Sabino Muñoz Labbé, - experto en "medicina interna para adultos y niños", "venérea y sifilíticas", tal y como él mismo se anunciaba en la prensa ${ }^{13}-$ y compañero de trabajo del propio Quinteros en la Morgue de Santiago ${ }^{14}$. Acostumbrado a colaborar con la justicia -y elaborando un informe de mayor extensión de lo habitual, dadas las circunstancias- el perito advirtió las carencias de los resultados presentados, sintiendo la ausencia de datos necesarios para saber si la víctima había sido "desflorada" o si se había procedido con violencia. Sin incluir referencias a la introducción digital criticada en el informe anterior, pues, como hemos comprobado en otros dos exámenes, ésta era una práctica empleada también por Muñoz Labbé ${ }^{15}$, este facultativo concluía, así, que el documento presentado se encontraba incompleto y que, por ello, no podía estimarse como prueba testimonial ${ }^{16}$. Ante estos resultados, el magistrado terminó por considerar que no existían suficientes antecedentes para condenar a López, desestimando la petición condenatoria del fiscal y absolviendo al reo definitivamente ${ }^{17}$.

\subsection{EL VALOR PROBATORIO DEL CONTAGIO SEXUAL}

Diez de las víctimas reconocidas (cinco en Santiago y cinco en Valparaíso) presentaron signos de padecer alguna afección genital, según los informes consultados. Tan sólo en uno de ellos, desarrollado en 1918 en el Hospital de niños Roberto del Río de Santiago, por el médico Ricardo Peralta, los resultados pudieron ser fruto de un examen bacteriológico, al detallarse que la víctima, de diez años, presentaba diversas lesiones -algunas en el himen, la horquilla y el perineo- y afirmar que "transcurrido el tiempo necesario" había podido comprobarse "la existencia de gonococus en la secrección vaginal de la enferma y por consiguiente la evidencia de la contaminación venérea (blenorragia)" lo que, sumado a las lesiones descritas, ante el criterio del facultativo, comprobaba que la violación se había producido $^{18}$.

Pese a las recomendaciones formales, las referencias a infecciones en los demás informes analizados carecieron de un examen microscópico, lo que imposibilitó el establecimiento de un diagnóstico fiable, dando lugar a exámenes cuestionables, surgidos de la observación clínica y sujetos a los divergentes criterios de los médicos observantes. 
En ocho de los nueve casos restantes, los exámenes fueron vagos y no ahondaron en la etiología de los síntomas hallados, refiriéndose a éstos de forma genérica, mediante las expresiones: "catarro vaginal (leucorrea)"19, "líquido mucoso abundante en vagina de origen catarral"20, "inflamación"21, "supuración"22, "vaginitis blenorrágica" ${ }^{23}$, "afección blenorrágica" ${ }^{24}$ y "vulvovaginitis" 25 .

En dos procesos, los médicos indicaron que las víctimas padecían "gonorrea", diagnóstico sujeto siempre a la observación clínica, como evidencia un informe privado, presentado como prueba por la madre de la víctima y elaborado en 1898 por el doctor Hugo Hahn, quien interpretó que el dolor y malestar que sentía en su uretra y genitales la niña J. L., de seis años, se debía a un contagio por gonorrea, presente de forma aguda en vagina y uretra ${ }^{26}$. Sin embargo, para el médico Daniel Carvallo, autorizado por el juez Bezanilla Silva, la niña se encontraba enferma de "vul$v a$ vaginitis, afección muy generalizada sobre todo entre la clase pobre"27. El "derrame mucopurulento" que producía esta enfermedad, así como la inflamación de los órganos genitales hacía que los padres de las niñas sospecharan de atentados al pudor que no habían existido, según el perito ${ }^{28}$. Frente a la declaración de la menor -quien relató ante el juez cómo un vecino había entrado en su casa y tenido acto carnal con ella a pesar de sus llantos- y de la vecina -testigo de los gritos de la niña- el informe médico tuvo mayor validez para las autoridades, quienes consideraron que éste demostraba que la violación no se había producido por lo que, pese a la posibilidad de que el acusado hubiese "ejecutado ciertos actos deshonestos con la mencionada menor", debía ser absuelto y puesto en libertad ${ }^{29}$

La imperante asociación entre infecciones sexuales y pobreza, unida a la ausencia de un análisis bacteriológico en la práctica forense, supuso, tanto en Santiago, como en Valparaíso, una mayor dificultad a la hora de demostrar las agresiones sexuales producidas en los entornos domésticos, algo acorde con una tendencia generalizada en el marco occidental, donde la constatación, a partir de los descubrimientos bacteriológicos de los años '70 y ' 80 del siglo XIX, de que estas infecciones eran muy frecuente en niñas sobre las que no figuraba ninguna denuncia de agresión, en vez de incrementar las investigaciones sobre posibles abusos intrafamiliares, se tradujo en una mayor relación entre infecciones sexuales con una higiene pobre, atribuyendo éstas al contacto con ropas, toallas u otros objetos sucios (Watson, 2011, p. 190).
De esta manera, en 1890 el perito Gana Urzúa atribuyó la presencia de leucorrea en el examen de los genitales de una víctima a una probable "falta de aseo" ${ }^{\prime 30}$, mientras que en 1898 el doctor Lira Erráruriz certificó en 1899 que la inflamación de la vulva, "acompañada de bastante supuración vaginal (blenorrágica)" en una niña de 4 años, supuestamente agredida por su tío paterno, podía "muy bien ser debida a actos de violencia o transmitida por contagio" pero que, "en vista de su corta edad" no tenía señales de haber sido violada ${ }^{31}$. En ninguno de los dos casos se ordenó analizar las supuraciones, para descartar que hubiesen sido causados por un contagio sexual $y$, pese a ellas, los acusados no fueron reconocidos.

Ante los diez casos de infecciones encontrados tras la revisión genital de las víctimas, de hecho, el reconocimiento de los agresores fue ordenado sólo en tres ocasiones. En todos ellos, la ausencia de signos de contagio visibles en los acusados, certificada por el médico de Valparaíso, Enrique Deformes, en 1898 y 1901 y por Sabino Muñoz Labbé en Santiago en 1917, conllevó la absolución judicial de éstos, al considerar que el delito no quedaba demostrado ${ }^{32}$. Como afirmó este último facultativo, tras examinar a una niña de ocho años, supuestamente violada por su padre, la ausencia de signos de contagio en el acusado, indicaba que la supuración genital de la víctima se debía a una "pésima higiene"33.

En todos estos casos, los procesados fueron absueltos por falta de pruebas. Ante esta situación, la normalización del uso del microscopio y la exploración sistemática de víctimas y agresores hubiese permitido una mayor precisión a la hora de determinar tanto posibles contagios como la autoría de los delitos, contrarrestando, de esa manera, la determinación de sentencias con base a la valoración de la probidad de los implicados en función de su condición socioeconómica o los preceptos de género.

Consideremos, al respecto, el proceso de 1898 contra los hermanos Cuitiño, acusados, junto con el teniente Wessel, de haber violado a una de sus sirvientas durante una fiesta que tuvo lugar en la casa de los primeros ${ }^{34}$. Además del testimonio de uno de los invitados, quien declaró ante el juez que había escuchado a los hermanos jactarse de la violación, el análisis médico, llevado a cabo por el doctor Deformes, indicaba que la víctima había sido desflorada sobre la fecha de la supuesta agresión, presentando varias contusiones en sus genitales que, junto con una "inflamación catarral", eran indicios de que se había procedido al coito "con violencia y repetidas veces", 
algo inusitado en este tipo de informes, pues sólo en dieciséis de los casos analizados los facultativos interpretaron las lesiones genitales como prueba del ejercicio de la fuerza ${ }^{35}$.

Frente a esta situación, los acusados trataron de desacreditar a la víctima, aludiendo a supuestos comportamientos sexuales no ajustados al recato, pudor y contención deseados por el ideal de feminidad imperante, afirmando que trabajó de sirviente en cantinas públicas, vendiendo "su cuerpo" y satisfaciendo "los apetitos carnales" de sus clientes ${ }^{36}$.

A esta estrategia de defensa, basada en el descrédito de la víctima mediante el cuestionamiento de su honorabilidad sexual, se unieron las declaraciones de dos de los acusados, ambos supuestos portadores de "enfermedades venéreas" altamente contagiosas. Tras constatar la presencia de una "afección blenorrágica aguda con chancros blandos (Ilagas) en el miembro" de uno de ellos y de "numerosas pequeñas cicatrices de pústulas por sarna (...) de posible carácter contagioso (...) alrededor de los órganos genitales" del segundo, pese a encontrar en la víctima "una vaginitis (catarral)", sobrevenida a causa de la violación, el perito consideró que ésta no estaba relacionada con los padecimientos de los acusados ${ }^{37}$. La ausencia de un análisis bacteriológico imposibilitó ofrecer mejores resultados periciales, situación frente a la que tanto el promotor fiscal Yáñez, como el juez Silva Domínguez, a pesar de los testimonios y pese a valorar que la declaración de la víctima era tenida digna de crédito "por su corta edad y estado de doncellez", resolvieron absolver a los acusados por falta de pruebas ${ }^{38}$.

\section{CONCLUSIONES}

La institucionalización y el desarrollo de la Medicina Legal en Chile, en el marco temporal considerado en este estudio, se produjeron dentro de parámetros higienistas y eugenésicos, que fueron reapropiados y reformulados dentro de una lógica cultural propia. Estos procesos, además de impulsar el diálogo con las dinámicas académicas imperantes en el contexto occidental y la transmisión del conocimiento científico, operaron como medios de fomento, desarrollo y difusión de valoraciones morales y culturales. La imbricación de estas últimas con los avances empíricos, el uso de referencias extranjeras y su inclusión en prestigiosas colecciones editoriales de índole científico-académica, dotó a los discursos resultantes de legitimación dentro de la comunidad intelectual, así como de autoridad e influencia fuera de la misma.
De esta manera, el tratamiento higienista de las llamadas "enfermedades venéreas" en la época promovió una serie de estereotipos de género y clasistas, que asociaban la peligrosidad del contagio, principalmente, al ejercicio de la prostitución y a los estratos socioeconómicos más bajos. Si bien nos encontramos en un momento histórico previo a las campañas estatales que buscaban popularizar ciertos conocimientos como medida pedagógica dirigida a la erradicación del contagio sexual, la base que antecedió a estos movimientos divulgativos fue el desarrollo de un determinado consenso académico internacional.

Al tiempo, a pesar de la tipificación penal del delito de violación como un acto ejecutable en mujeres, independientemente de su edad o condición, la promoción -también en las áreas médica y jurídica- de un ideal de feminidad basado en el recato y el pudor, promovió, en la práctica, la institucionalización de un sistema forense protector sólo de aquellas víctimas capaces de demostrar haber cumplido con dicho ideal.

Asimismo, en relación con las infecciones de transmisión sexual, los paulatinos avances que se sucedieron en su conocimiento nosológico y profiláctico y, en concreto, en su comprobación pericial como vestigio probatorio de la comisión del delito de violación, no encontraron una correlación directa en la práctica forense desarrollada en los tribunales de Santiago y Valparaíso. De esta manera, a los múltiples vacíos e incógnitas que revestían los discursos médicos sobre las características y los tiempos de incubación de las enfermedades consideradas, en la cotidianidad pericial se sumaron la escasez de recursos técnicos y formativos junto con un marcado desinterés por desarrollar mecanismos eficientes de comprobación relativos a esta tipología delictiva y una marcada desconfianza de las autoridades frente a las víctimas, niñas y mujeres pobres en su mayoría.

Consideramos, por tanto, que la valoración de estas afecciones como método probatorio criminal obstaculizó en mayor medida la demostración de un delito de violación, dentro de una actuación pericial que, en varias ocasiones, se desarrolló más como parte de un proceso burocrático estandarizado que como el establecimiento de una verdadera comprobación material de la acción delictiva.

\section{AGRADECIMIENTOS}

Trabajo financiado por proyecto ANID FONDECYT Postdoctorado № 3180184 


\section{NOTAS AL FINAL}

1 El vocablo "venéreo" fue conmunmente empleado desde el siglo XVII en Europa y América para aludir a infecciones de transmisión sexual desde una perspectiva androcéntrica, remarcando su relación con el placer carnal a través de Venus, diosa femenina del amor dentro de la mitología romana. Considerando su sustitución desde finales del siglo XX por los términos "enfermedad de transmisión sexual" (ETS) o "infección de transmisión sexual" (ITS), su transcripción en este artículo es crítica y responde al uso histórico del mismo.

2 Artículo 361 del Código Penal de 1874. (1889) Código Penal de la República de Chile, Santiago, Imprenta Nacional, p. 771.

3 Algunas obras relacionadas con la temática de estudio pero emplazadas en otros periodos o áreas son: Celis, 2013; González 2018 y Martín, 2015.

4 Incluimos aquí la obra de Muñoz San Martín, 1911 ya citada, por contener el desarrollo de las clases de Medicina Legal impartidas por el profesor Ramírez Frías, 1907.

5 Con objeto de evitar la propagación de las "enfermedades venéreas", la Municipalidad de Santiago reglamentó la prostitución en 1896 (Gálvez, 2014, p. 77). La de Valparaíso hizo lo mismo en 1898 (Gálvez, 2017, p. 92).

6 ANHCh, Santiago, Criminal, 1894, Caja 1136, exp. 65, f. 2; ANHCh, Santiago, Criminal, 1896, caja 1167, exp. 13, f. $3 v$ y ANHCh, Valparaíso, Criminal, 1900, caja 50193, exp. 7, f. 3v.

7 ANHC, Valparaíso, Criminal, 1900, caja 50193, exp. 13, f. 12.

8 Pese a revisar un total de cien expedientes, encontramos informes médicos en cuarenta de los cincuenta casos de Santiago y en cuarenta y ocho de los cincuenta de Valparaíso.

9 ANHCh, Valparaíso, Criminal, 1898, caja 50181, exp. 31, f. 3 y ANHCh, Santiago, Criminal, 1892, caja 1104, exp. 46, f. $1-34 \mathrm{v}$.

10 Tan sólo dos de las víctimas presentaron una posición acomodada. ANHCh, Santiago, Criminal, 1896, caja 1167, exp. 13, ff. 1-20 y ANHCh, Valparaíso, Criminal, 1900, caja 500193, exp. 7, ff. 1-52.

11 ANHCh, Santiago, Criminal, 1914, caja 1295, exp. 7, f. 6.

12 ANHCh, Santiago, Criminal, 1914, caja 1295, exp. 7, f. 8.

13 "Guía Profesional: Médicos", La Nación, 1 de agosto de 1917, año 1, n. 215, f. 6.

\section{BIBLIOGRAFÍA}

Araya, Alejandra (1995), “Cuerpos aprisionados y gestos cautivos: el problema de la identidad femenina en una socie-dad tradicional (Chile 1700-1850)", Nomadías, 1, pp. 71-84.

Araya, Alejandra (2004), "La pureza y la carne: el cuerpo de las mujeres en el imaginario político de la sociedad colonial", $R e$ vista de Historia Social y de las Mentalidades, 8 (1): pp. 67-90.

Araya, Alejandra (2015), "Violación, aborto y embriones: las fronteras del estado laico y de una sociedad de derechos en perspectiva histórica". En: Coloquio. Violación y aborto:
14 Junto con Diago A. Bahamondes y Luis Quinteros Encina, Labbé fue uno de los tres médicos legistas que conformaron el personal de la Morgue de Santiago desde que esta institución pasara a depender de los tribunales de justicia en 1915. "Morgue de Santiago. Decreto que reglamenta sus servicios". En (2015), Boletín de Leyes y Decretos del Gobierno, Libro LXXXIV, Santiago, Editor no identificado, p. 933.

15 ANHCh, Santiago, Criminal, 1920, caja 1463, exp. 50, f. 2 y ANHCh, Santiago, Criminal, 1920, caja, 1474, exp. 42, f. 3.

16 ANHCh, Santiago, Criminal, 1914, caja 1295, exp. 7, ff. 128v129.

17 ANHCh, Santiago, Criminal, 1914, caja 1295, exp. 7, f. 143v.

18 ANHCh, Santiago, Criminal, 1918, caja 1404, exp. 2, ff. 1-15.

19 ANHCh, Santiago, Criminal, 1890, caja 1081, exp.1, f. 4.

20 ANHCh, Santiago, Criminal, 1890, caja, 1081, exp. 31, ff. 1-2.

21 ANHCh, Valparaíso, Criminal, 1898, caja 50183, exp. 28, f. 13.

22 ANHCh, Santiago, Criminal, 1899, caja 1211, exp. 2, ff. 2; ANHCh, Santiago, Criminal, 1917, caja 1385, exp. 21, f. 1v.

23 ANHCh, Valparaíso, Criminal, 1894, caja 50065, exp. 9, ff. 2.

24 ANHCh, Valparaíso, Criminal, 1894, caja 50065, exp. 3, f. 1v.

25 ANHCh, Valparaíso, Criminal, 1898, caja 50183, exp. 6, f. 2v.

26 ANHCh, Valparaíso, Criminal,, 1898, caja 50183, exp. 6, f. 1.

27 ANHCh, Valparaíso, Criminal,, 1898, caja 50183, exp. 6, f. 4.

28 ANHCh, Valparaíso, Criminal,, 1898, caja 50183, exp. 6, f. 4.

29 Citación del promotor fiscal de la Corte de Apelaciones de Valparaíso en: ANHCh, Valparaíso, Criminal, 1898, caja 50183, exp. 6, f. 8.

30 ANHCh, Santiago, Criminal, 1890, caja 1081, exp.1, f. 4.

31 ANHCh, Santiago, Criminal, 1899, caja 1211, exp. 2, f. 3.

32 ANHCh, Valparaíso, Criminal, 1898, caja 50183, exp. 28, ff. 1-34; Valparaíso, 1901, 50047, exp. 2, ff. 1-12 y Santiago, 1917, caja 1385, exp. 21, ff. 1-28.

33 ANHCh, Santiago, Criminal, 1917, caja 1385, exp. 21, f. 8v.

34 ANHCh, Valparaíso, Criminal, 1898, caja 71, exp. 9, ff. 1-84.

35 ANHCh, Valparaíso, Criminal, 1898, caja 71, exp. 9, f. 5.

36 ANHCh, Valparaíso, Criminal, 1898, caja 71, exp. 9, f. 57.

37 ANHCh, Valparaíso, Criminal, 1898, caja 71, exp. 9, f. 43

38 ANHCh, Valparaíso, Criminal, 1898, caja 71, exp. 9, ff. 78-78v.

Historia, justicia y Derechos en Chile. Santiago, Universidad de Chile, pp. 6-12.

Baratta, Alessandro (2004), Criminología Crítica y Crítica del Derecho Penal. Introducción a la sociología jurídico-penal, Buenos Aires, Siglo XXI, p. 258.

Barona, Josep Lluís (2016), “Enfermedades venéreas: un problema sanitariointernacional en 1900", Medicina e Historia, 4, pp. 4-20.

Bowen, Elliot (2013), “Limits of the Lab: Diagnosing "Latent Gonorrhea" 1872-1910", Bulletin of the History of Medicine, 87, pp. 63-85. 
Boza, Dávila (1898), "Contra la sífilis", Revista Médica de Chile, 26, pp. 36-38.

Brangier, Víctor; Barriera, Darío (2015), "Lenguajes comunes en 'justicias de jueces'. Tratamientos historiográficos y fondos judiciales en Chile y Argentina". Revista de Humanidades, 32: pp. 227-258.

Brito, Alejandra (2005), De mujer independiente a madre, de peón a padre proveedor. La construcción de identidades de género en la Sociedad Popular Chilena. 1880-1930. Concepción, Ediciones Escaparate, 168p.

Cabrera, Miguel Ángel (2003), "La crisis de la historia social y el surgimiento de una historia postsocial", Ayer, 51: pp. 201224.

Cano Andreu, José (1921), "Contribución al estudio de las secreciones genitales", Revista Médica de Chile, 49, pp. 653-654.

Celis Valderrama, Nicolás (2013), "El "morbo gálico" (sífilis) en la Época Colonial tardía. La tensión entre la moralidad jurídicoreligiosa y la racionalidad higienista: el caso de la esclava Petrona. Santiago de Chile,1806-1808", Revista Historia Social de las Mentalidades, 17 (2), pp. 75-103, [en línea], disponible en: http://www.revistas.usach.cl/ojs/index.php/historiasocial/ article/view/1544/1422, [consultado el 22/08/2019].

Conrad, Joseph (2016), What Is Global History?, Princetown, Princeton University Press, p. 312.

Coutts, Waldemar (1929), El contagio venéreo como delito. Razones biológicas y jurídicas, Boletín de la Oficina Sanitaria Panamericana, 8 (7), pp. 654-663.

Cruz-Coke Madrid, Ricardo (1995), Historia de la Medicina Chilena, Santiago, Andrés Bello, p. 458.

Durán Sandoval, Manuel (2017), "Sexualidad, producción y trabajo en el discurso higienista y eugenésico en Chile y Argentina, 1860-1930", Revista Nomadías, 23, pp. 31-52.

Editorial (1915), "Campaña Internacional contra las enfermedades venéreas", Revista Médica de Chile, 43, pp. 325-331.

Elguero, Ramón (1857), “Medios que convendría emplear para contener los progresos de la sífilis", Anales de la Universidad de Chile, 15, pp. 16-29.

Fabregat Peredo, Mario (2019), “Evolución de la Medicina Legal en Chile: una aproximación através de las autopsias practicadas por el doctor Eduardo Lira Errázuriz, entre 1893 y 1905", Asclepio, 71(1), [en línea], doi: 10.3989/asclepio.2019.04

Fernández Navas, Pamela (2015), "La otredad incivilizada en el mundo del salitre. El caso de indígenas bolivianos e inmigrantes asiáticos en Tarapacá, 1900-1910", Polis, 14 (42), [en línea]: https://scielo.conicyt.cl/scielo.php?script=sci_ arttext\&pid=S0718-65682015000300005

Fournier, Alfred (1906), "La sífilis de las mujeres honradas", Revista Médica de Chile, 34, pp. 341-343.

Gálvez Comandini, Ana (2014), "Lupanares, burdeles y casas de tolerancia: tensiones entre las prácticas sociales y la reglamentación de la prostitución en Santiago de Chile: 18961940", Revista Tiempo Histórico, 5 (8), pp. 73-92.

Gálvez Comandini, Ana (2017), "La prostitución reglamentada en latinoamérica en la época de la modernización. Los casos de Argentina, Uruguay y Chile entre 1874 y 1936", Historia 396,1 , pp. 89-118.

González-Gómez, Yessica (2018), “'Consiguió su instinto dejándome enferma...'. Alcances y prácticas de justicia frente al delito de violación en Concepción en el siglo XIX", Revista Austral de Ciencias Sociales, pp. 41-58, [en línea], doi: 10.4206/rev.austral.cienc.soc.2017.n32-03.

Hutchison, Elizabeth (2006), Labores propias de su sexo. Género, políticas y trabajo en Chile urbano 1900-1930, Santiago, LOM Ediciones, 346p.

Labarca, Catalina (2008), "Todo lo que usted debe saber sobre las enfermedades venéreas". Las primeras campañas de educación sexual estatales entre 1927 y 1938". En: Zárate Campos, María Soledad (comp.), Por la salud del cuerpo. Historia y políticas sanitarias en Chile. Santiago, Ediciones Universidad Alberto Hurtado, pp. 81-129.

Lea-Plaza, Hugo (1913), "La sífilis", Revista Médica de Chile, 31, pp. 84-104.

Ledezma, Gerson (2006), "Chile en el primer Centenario de la Independencia en 1910: Identidad y crisis moral", Historia y Espacio, 26, [en línea], doi: https://doi.org/10.25100/hye.v2i26.1649

Liga Chilena de Higiene Social (1921), "Estatutos de la Liga de Higiene Social", Revista Médica de Chile, 39, pp. 239-243.

Locke, David (1997), La ciencia como escritura, Madrid, Cátedra-Universitat de València, p. 270.

Martín Bascuñán, Jorge (2015), “El higienismo y la noción de contagio. El caso de la sífilis en los Anales de la Universidad de Chile". Intus - Legere Historia, 9(1), pp. 69-86. [en línea], doi: 10.15691/07198949.1852015

Middleton, Florencio (1884), “Observaciones Clínicas. Enfermedades venéreas y sifilíticas. Importancia de su estudio", Revista Médica de Chile, 13, pp. 429-432.

Moore, Eduardo (1912), "Origen de la sífilis", Revista Médica de Chile, 40 (3), pp. 81-91.

Morimoto, Amelia (ed.) (2004), Cuando Oriente llegó a Améri$c a$. Contribuciones de inmigrantes chinos, japoneses y coreanos. Nueva York, Banco Interamericano de Desarrollo, $346 \mathrm{p}$.

Muñoz San Martín, Francisco (1911), Estudios sobre Antropología Jurídica (Medicina legal): obra escrita con arreglo al programa universitario formado para el Curso de Derecho. Comprende las disposiciones sustantivas y de procedimiento relativas a cuestiones médico-legales, contenidas en los códigos Chilenos y en Leyes especiales, comparadas conalgunas disposiciones de Legis/aciones Extranjeras, Santiago, Imprenta y Encuadernación "Chile", p. 264.

Núñez Galeno, Domingo (1927), Del delito de contagio venéreo, Santiago, Taleres de "El Diario llustrado", p. 90.

Puga Borne, Federico (1900), Compendio de Medicina Legal. Adaptado a la Legislación Chilena, Santiago, Imprenta Cervantes, p. 896.

Quinlan, Andrea (2007), The Technoscientific Witness of Rape: Contentious Histories of Law, Feminism, and Forensic Science. Toronto, University of Toronto Press, p. 272. 
Ramírez Frías, Tomás (1907), Apuntes de medicina legal, Santiago, Imprenta y encuadernación, p. 212.

Ríos, Conrado (1894), "El tratamiento de la blenorragia”, Revista Médica de Chile, 22, pp. 95-109.

Robertson, Roland; Giulianotti, Richard (2006), "Fútbol, globalización y glocalización”, Revista Internacional de Sociología, 64 (45), pp. 9-35.

Robertson, Roland (2003), “Glocalización tiempo-espacio y homogeneidad -heterogeneidad". En: Monedero Fernández-Gala, Juan Carlos. Cansancio del Leviatán: problemas políticos de la mundialización. Madrid, Trotta, pp. 261-284.

Rubin, Gayle (1986), "El tráfico de mujeres: notas sobre la economía política del sexo", Nueva Antropología, 8 (30), pp. 95-145.

Rudolph, Julia (2008), Gender and the Development of Forensic Science: A Case Study. The English Historical Review, 123(503): pp. 924-946.

Sánchez Delgado, Marcelo (2014), “Eugenesia: ciencia y religión. Una aproximación al caso chileno", Revista de Historia Social, 18 (1), pp. 59-83.

Sánchez Delgado, Marcelo (2014a), “La Teoría De La Degeneración En Chile (1892-1915)”, Historia 47, pp. 375-400.

Sánchez Delgado, Marcelo (2015), Chile y Argentina en el escenario eugénico de la primera mitad del siglo XX, (Tesis Doctoral), Santiago, Universidad de Chile, p. 354.

Sanhueza Cerda, Carlos (2018). "Introducción". En: Sanhueza Cerda, Carlos (ed.), La movilidad del saber científico en América Latina. Objetos, prácticas e instituciones (siglos XVIII al $X X)$. Santiago, Editorial Universitaria, pp. 13-18

Scott, Joan W. (1990), “El género: una categoría útil para el análisis histórico". En: Amelang, James S. y Nash, Mary (eds.),
Historia y Género: Las mujeres en la Europa Moderna y Contemporánea. Valencia, Universidad de Valencia, pp. 23-58.

Sierra, Lucas (1914), "Resumen de algunos de los trabajos presentados al XVII Congreso internacional de Medicina celebrado en Londres", Revista Médica de Chile, 42 (1), pp. 20-26.

Sociedad Médica de Chile (1889), "Sesión en 6 de agosto de 1889", Revista Médica de Chile, 18, pp.120-125.

Sociedad Médica de Valparaíso (1917), "Profilaxia de las enfermedades venéras Revista Médica de Chile, 43, pp. 365-367.

Swisser, H. (1899), "Algunas consideraciones sobre la blenorragia en la mujer", Revista Médica de Chile, 27, pp. 465-468.

Subercaseaux, Bernardo (2007), Historia de las ideas y de la cultura en Chile, tomo IV, Santiago, Editorial Universitaria, 276 p.

Urbina, María Ximena (2001), Los conventillos de Valparaíso 1880-1920. Tipología, sociabilidad y percepción de una vivienda urbano-marginal, Valparaíso, Universidad Católica de Valparaíso, 274p.

Vega, Ramón E. (1880), "Prensa francesa", Revista Médica de Chile, 9, pp. 245-248.

Vetö, Silvana (2014), "Psicoanálisis, higienismo y eugenesia: educación sexual en Chile", 1930-1940, Nuevo Mundo Mundos Nuevos, 14, [en línea], doi: 10.4000/nuevomundo.66920

Vidal Vargas, Luisa (1930), El contagio venéreo en la medicina legal, Santiago, Imprenta la República, p. 62.

Vigarello, Georges (1999), Historia de la violación (siglos XVI-XX). Madrid, Cátedra, p. 394.

West, Candance; Lazar, Michele M.; Kramarae, Cheris (2000), “El género en el discurso". En: Van Dijk, Teun A. (comp.), El discurso como estructura y proceso. Barcelona, Gedisa, pp. 179-212.

Zañartu, Aníbal (1894), "Reglamento para los médicos de ciudad", Revista Chilena de Hijiene, 1 (1), pp. 657-660. 